This is a self-archived version of an original article. This version may differ from the original in pagination and typographic details.

Author(s): Junttila, Juha-Pekka; Vataja, Juuso

Title: Economic policy uncertainty effects for forecasting future real economic activity

Year: 2018

Version: Accepted version (Final draft)

Copyright: (c) 2018 Elsevier B.V.

Rights: $C C B Y-N C-N D 4.0$

Rights url: https://creativecommons.org/licenses/by-nc-nd/4.0/

Please cite the original version:

Junttila, J.-P., \& Vataja, J. (2018). Economic policy uncertainty effects for forecasting future real economic activity. Economic Systems, 42(4), 569-583.

https://doi.org/10.1016/j.ecosys.2018.03.002 


\title{
Economic Policy Uncertainty Effects for Forecasting Future Real Economic Activity
}

\author{
Juha Junttila* \\ University of Jyväskylä \\ School of Business and Economics \\ P.O. Box 35 \\ FI-40014 Jyväskylä \\ FINLAND \\ e-mail: juha.-pekka.junttila@jyu.fi
}

\author{
Juuso Vataja \\ School of Accounting and Finance \\ University of Vaasa \\ P.O. Box 700 \\ FI-65101 Vaasa \\ FINLAND \\ e-mail: jpv@ univaasa.fi
}

February 13, 2018

\begin{abstract}
Recently introduced measures for Economic Policy Uncertainty (EPU) included in the data from 1997 - 2016 have a role in forecasting out-of-sample values for the future real economic activity for both the euro area and the UK economies. The inclusion of EPU measures, either for the US, the UK or for overall European economies, improves the forecasting ability of models based on standard financial market information, especially for the period before the 2008 global crisis. However, during and after the crisis period, the slope of the yield curve and excess stock market returns improves the out-of-sample forecast performance the most compared to an AR-benchmark model. Hence, the EPU information is important in times of normal business cycles, but it might contain similar information components to the financial market return variables, during turbulent crisis periods in the financial markets and in the real economy.
\end{abstract}

Keywords: Financial markets, Leading indicators, Macroeconomic forecasting, Time series, Uncertainty

JEL classifcation: E17, E44, E66, G01

* Corresponding author. 


\title{
Economic Policy Uncertainty Effects for Forecasting Future Real Economic Activity
}

\begin{abstract}
Recently introduced measures for Economic Policy Uncertainty (EPU) included in the data from 1997 - 2016 have a role in forecasting out-ofsample values for the future real economic activity for both the euro area and the UK economies. The inclusion of EPU measures, either for the US, the UK or for overall European economies, improves the forecasting ability of models based on standard financial market information, especially for the period before the 2008 global crisis. However, during and after the crisis period, the slope of the yield curve and excess stock market returns improves the out-of-sample forecast performance the most compared to an AR-benchmark model. Hence, the EPU information is important in times of normal business cycles, but it might contain similar information components to the financial market return variables, during turbulent crisis periods in the financial markets and in the real economy.

Key words: Financial markets, Leading indicators, Macroeconomic forecasting, Time series, Uncertainty

JEL classification: E17, E44, E66, G01
\end{abstract}




\section{Introduction}

Policy makers around the world are currently facing increasingly challenging decisionmaking situations when attempting to formulate the optimal economic policy paths for the future. For example, central bankers have to take into account the fact that extreme monetary policy decisions might at least have a quick and strong effect on the financial markets in the short run, and in the long run, they are (or should be) obviously designed to have positive effects, especially on the real economic activity and on the control of inflation at the aggregate level of the economy. The policy decisions have to be made based on the data regarding both the past behavior and the future predictions of the relevant economic variables. Hence, when the conditions in the overall economy suddenly change, e.g., due to some unexpected exogenous shocks such as overall financial market crashes or sudden country-specific shocks in international trade, the recent economic policy decisions might prove to be already inconsistent for the near future. In other words, economic policy decision making involves a great deal of uncertainty over time.

The Federal Open Market Committee (2009) and the IMF $(2012,2013)$ have suggested that uncertainty about the U.S. and European fiscal, regulatory, and monetary policies had a strong effect on the steep economic decline in 2008-2009 and the slow recovery rates after that. Partly due to this observation, even though the economic policy uncertainty has always been prevalent, only recently have economists attempted to systematically quantify the important phenomenon of economic policy uncertainty. The pioneering work has been made by Baker, Bloom and Davis (2016 and 2015, see also e.g., Baker et al. 2014). Roughly, the main idea in the calculated quantitative measure for Economic Policy Uncertainty, i.e., the EPU-index (see www.policyuncertainty.com) is to quantify the nature of the information in the mass media (especially newspapers) on the key terms related to the many dimensions of economic policy decision making. For example, for the US EPU-index, the triple of the terms searched for mainly contains some combinations of the following words: economic or economy; uncertain or uncertainty; and one or more of congress, deficit, Federal Reserve, legislation, regulation, or White House. In Baker et al. (2016), it is shown that the index captures many important events or periods of increasing uncertainty in the US economic policy, such as tight 
presidential elections, the Gulf Wars, and the 9/11 attacks. In addition to the US case, the EPU index is currently also calculated at many frequencies for 11 other countries and economic areas ${ }^{1}$.

It is important to distinguish between the economic policy uncertainty that we are interested in this study and the overall uncertainty of economic conditions that can be divided roughly between financial market uncertainty and macroeconomic uncertainty (that might arise from the firms' level of uncertainty about their future performance possibilities). Both these can be measured by various kinds of single variable or composite measurement proxies. For example, Jurado, Ludvigson and Ng (2015) and Ludvigson, Ma and Ng (2016) provide detailed theoretical foundations and empirical analyses for the idea that every kind of uncertainty should basically be based on a more general, even though not necessarily structurally well-defined, model (enabling also the endogeneity of the uncertainty) and not measured just based on a simple indicator or index value of something. However, instead of attempting to use a highly sophisticated and analytically demanding measure for overall uncertainty in the economy, in this paper, we are especially interested in including a more meta-analysis-based index number, i.e., the Economic Policy Uncertainty (EPU) index, to a financial market-based forecasting model for future economic activity. Hence, we are not trying to find any kind of an improvement to the measure of uncertainty but merely want to determine the role of this newly established information variable among a set of other

\footnotetext{
${ }^{1}$ As the most recent step, building on the original work of Baker et al. (2016), Davis (2016) has constructed a Global Economic Policy Uncertainty (GERPU) Index, that is, a GDP-weighted average of national EPU indices for 16 countries that account for two-thirds of global output. In the GEPU, each national index reflects the relative frequency of own-country newspaper articles that contain a trio of terms pertaining to the economy, uncertainty and policy-related matters. Examples of how this index reacts to economic news are its sharp rises in reaction to the Asian Financial Crisis, the 9/11 terrorist attacks, the U.S.-led invasion of Iraq in 2003, the Global Financial Crisis in 2008-09, the European immigration crisis, concerns about the Chinese economy in late 2015, and, as the latest potentially global shock, the Brexit referendum in June 2016. It has heavily reacted also to the sovereign debt and banking crises in the Eurozone, the intense partisan battles over fiscal and healthcare policies in the United States, and a generational leadership transition in China. Furthermore, it seems to point towards ongoing global political unrest because the average value of the GEPU Index was 60 percent higher from July 2011 to August 2016 than in the previous fourteen and one-half years and even 22 percent higher than in 2008-09.
} 
(financial market based) indicator variables, when forecasting the future activity in the euro area and the United Kingdom economies.

Considering the forecasting content of EPUs both at the single (individual) country (UK) and at the aggregate economic (euro) area levels brings out a more versatile view of the forecasting potential of the variable than concentrating merely on a single country level. Moreover, this setup gives us a chance to discuss the prominent effects of the very recent BREXIT decision in terms of forecasting future real economic activity, both in the euro area and in the UK.

Our empirical analysis utilizes financial market variables as the fundamental information containing forecasting power for the future real economic activity measured by changes in the industrial production index. ${ }^{2}$ We use monthly data from both the euro area and the UK for the time period of 1997 - 2016 and find that the forecasting power of especially the slope of the yield curve is strong, and in addition, especially during and after the most recent economic crisis, the excess stock market return forecasts the future real economic performance in the euro area as assumed a priori, i.e., the previously observed positive excess returns forecast improving real economic activity in the future. In the UK data, the stock market forecasting power is very strong for the time period before the crisis, but the slope of the yield curve in that period does not have any forecasting power for future real activity. Nevertheless, in both economic areas and for both the subsamples before and after the crisis, the inclusion of Economic Policy Uncertainty improves the forecast ability of the financial market model in the 12-month horizon in some cases ${ }^{3}$.

\footnotetext{
${ }^{2}$ Industrial production has been commonly used as a proxy for economic activity in a number of previous studies, e.g., Junttila and Korhonen (2011), Drechsel and Schenfele (2012), and Colombo (2013). Arguably, the gross domestic product (GDP) would be a more natural measure for economic activity. However, because our forecasting analysis is based on a rolling five-year estimation window in which we want to have a high enough number of observations for each sub-sample regression and because the GDP figures are not available on a monthly basis, we use industrial production as a proxy for economic activity.

${ }^{3}$ The results based on other than a 12-month forecast horizon are available upon request. For example, for the 24-month horizon, the European EPU effects would seem to be the most important for the future euro area activity prior to the 2008 crisis, but then, the policy uncertainty from the UK dominates in terms of improving the forecasting power. However, in the UK data for the same longest forecast horizon, the European policy uncertainty itself would seem to be the most relevant before the crisis, but after the crisis, the financial variables
} 
The remaining part of this paper is organized as follows. In section two, we first give the literature view on some earlier studies utilizing mainly financial market information in forecasting the future values of macroeconomic variables, after which we take a look at the short list of previous studies utilizing the EPU index in this context. The section ends with a description of our main regression model that is based on combining the main findings in the literature described above. In section 3, we report the details of our data, estimation methods and the empirical results from our forecast exercises, and section 4 gives conclusions and suggestions for future research.

\section{Forecasting real activity with financial market information}

\subsection{Findings utilizing only financial market data}

The famous study of Stock and Watson (2003) is perhaps the most influential work regarding the forecasting ability of financial market information for future values of macroeconomic variables. After a large literature review on the role of financial market information in forecasting future real growth and inflation, they utilize a set of 43 variables from seven OECD countries in their own forecast exercise and find four main results. First, they find that some asset prices have substantial and statistically significant marginal prediction power for macro variables at some times in some countries, and this is more evident for forecasting output growth than for forecasting inflation. Second, they find that forecasts based on individual indicators are unstable over time. Third, using in-sample significance tests, e.g., Granger-causality analysis, does not guarantee that the potentially identified predictive relation is stable. Fourth, combining the information in the various predictors might enable the circumvention of the worst instability problems in these kinds of analyses.

On the whole, the work by Stock and Watson (2003) launched an intensive wave of research in an effort to find the best possible financial market-based indicators for the various forms of future macroeconomic activity. The most recent studies have found that the period of the

in addition to the UK policy uncertainty are the most important in improving the out-of-sample forecast performance. 
Great Recession after 2008 has had a significant effect on the usefulness of financial market variables in this respect. For example, Chauvet and Senyuz (2016) identified the joint dynamic behavior of the Treasury bill yield curve components and the macro economy for predicting business cycle turning points. They found that in the monthly data from August 1971 to December 2012, there is a strong relationship between the yield curve and the economic situation, and their dynamic factor model had strong predictive value relative to some alternative specifications, both in the in-sample and out-of-sample analyses and using revised and real time unrevised data. One of the previous studies that has also focused specifically on the most recent crisis period is the study by Drechsel and Scheufele (2012), who used leading indicator models for forecasting the development of the German economy right before and during the latest crisis. They focused especially on forecasting industrial production in Germany and used many types of indicators, such as survey-based measures, financial market indicators, and composite leading indicators. Their main emphasis was in using the financial indicators as predictors of real activity because this recession (like many others) was also seen to be rooted in the financial sector disturbances (see also Stock and Watson 2003, for the earlier findings). Their general finding was that average forecasting errors increased dramatically during the recession. Most of the indicators correctly indicated a slowdown prior to the crisis, but none of them predicted the sharpness of the downturn accurately. Moreover, while the overall forecasting performance of the indicator models worsened during the crisis, the relative performance of certain individual indicator (term and risk spread based) forecasts improved substantially. In earlier studies, e.g., Duarte, Venetis and Paya (2005) also have found that the yield spread, i.e., the difference between the longterm interest rate and a short-term interest rate, performs well as a leading indicator for the aggregate euro area one-year-ahead of the annual real growth of the economy. Moreover, they also found that the EMU and US yield spreads have been successful predictors of EMU recessions, in the data from $1970-2000$.

Bluedorn, Decressin and Terrones (2016) also focused specifically on the forecasting power of asset prices and returns in predicting the beginnings of recessions in G-7 countries. They found that both the equity and housing market price drops have a substantial marginal effect 
on the likelihood of a new recession, together with the equity market risk or uncertainty. Their findings remained the same even after controlling for the inclusion of the traditional forecasting variables, i.e., the term spread and oil prices, in the probability model. The role of financial market volatility was highlighted also in Ferrera, Marsilli and Ortega (2014), who used a MIxed DAta Sampling (MIDAS) approach to forecast the quarterly output growth in the US, France and UK based on data from financial markets sampled at various higher frequencies. Their main finding was that financial market volatility has been useful in improving the forecast accuracy of gross domestic product predictions based on financial market data, since the beginning of the Great Recession from 2008 onwards.

\subsection{Economic policy uncertainty (EPU) and macro economy}

Due to the fairly recent introduction of the EPU index of Baker et al. (2016 and 2015), only few studies so far have utilized it explicitly for forecasting the future macroeconomic performance. The list of papers up until now includes e.g., Bordo, Duca and Koch (2016), Chang, Chen, Gupta and Nguyen (2015), Stockhammar and Österholm (2015), Karnizova and Li (2014), and Colombo (2013).

Using monthly data from the period of January 1999 to June 2008, Colombo (2013) focused specifically on the effects of US policy uncertainty on the euro area macroeconomic aggregates, based on Structural VAR models. She found a statistically significant negative connection between the US economic policy uncertainty shocks and the European industrial production and aggregate price indexes, and the US policy uncertainty effects were quantitatively larger than the corresponding euro area effects for these two main macro variables. Karnizova and Li (2014) utilized quarterly data from First Quarter 2006 to First Quarter 2013 in their recession forecasting probit model and found that EPU indexes (both the so called aggregate index and its newspaper-based component) help predict the forthcoming US recessions and that the policy uncertainty indexes also improved the forecasts based on models containing financial market variables. The newspaper-based index seemed to even outperform the traditionally well-performing term spread variable, in longer horizons. 
Stockhammar and Österholm (2016) applied Bayesian VAR models and spectral analysis to the examination of the effects of US economic policy uncertainty on Swedish GDP growth for quarterly data from 1988 - 2013. They found that increasing US policy uncertainty clearly negatively affects Swedish economic growth, especially through the effects on investment and export growths.

As we mentioned already in the introductory section, the FOMC (2009) and the IMF (2012, 2013) have suggested that uncertainty about the US and European economic policies may have had a strong effect on the steep economic decline in 2008-2009 and slow recovery rates after that. One of the most recent studies that finds indirect empirical support for this argument is Bordo, Duca and Koch (2016). They found that for the years 1985 - 2014, economic policy uncertainty has had a significant negative effect on the aggregate bank credit growth. Furthermore, because many studies have found important macroeconomic effects of bank lending growth on the macro economy ${ }^{4}$, their results support the argument that high economic policy uncertainty may have slowed the US economic recovery from the Great Recession of 2008-2009 by restraining overall credit growth through the bank lending channel. This result is highly relevant and very interesting also for the analysis of all our data. Based on viewing the time series of the EPU indexes for the US, Europe and separately also for the UK data, we will see that when the economic policy uncertainty indicators started to rise both in the US and everywhere in Europe around 2007, the index rose more in Europe than in the US, after the Great Recession. In addition, it has subsequently receded markedly less in Europe than in the US. This finding gives an interesting starting point for our forecasting exercise, for which we will next formulate our main regression model.

\subsection{The forecasting model}

The economic policy uncertainty has very recently been reported to have effects also on, for example, the stock-bond correlations (e.g., Li et al. 2015) and the stock prices in OECD countries (see Chang et al. 2015). Hence, in our paper, the main novel idea is to analyze

\footnotetext{
${ }^{4}$ See e.g. Aron et al. (2012), Basset et al. (2014), and Wu \& Xia (2016).
} 
thoroughly the role of economic policy uncertainty in the models that utilize financial market information for forecasting the future values of real macroeconomic activity. The fundamental form of our forecasting model is based on the previous studies by, e.g., Stock and Watson (2003), Bordo and Haubrich (2008a and 2008b), Junttila and Korhonen (2011), and Kuosmanen, Nabulsi and Vataja (2015). The common theme in all these studies has been to use only asset market return variables for forecasting the future values of various kinds of macroeconomic variables, like, for example, GDP and/or industrial production growth, inflation and real exchange rates. As originally stated also in the abovementioned fundamental study by Stock and Watson (2003), the more recent papers listed above have found that the short-term interest rates, term spreads, and stock returns are among the most important explanatory asset market variables for forecasting future values of either economic activity or inflation. Hence, based on a number of previous findings, at the first stage of our analysis, we will utilize the excess stock market returns, short-term interest rates and the term spread in our forecasting model for the future real economic activity. However, as a novel application, we will augment the standard financial market-based forecasting models with the economic policy uncertainty (EPU) index. We will concentrate in forecasting the real economic activity in the euro area and the UK and expand the abovementioned scant literature on the role of economic policy uncertainty in forecasting the future real economic activity by:

1. Using monthly data to reveal the short-term dynamics of the policy effects and the effects of financial market returns on future real economic activity in the euro area and UK;

2. Analyzing thoroughly the possibly changing roles of financial market return variables and the EPU index in forecasting the future real activities before and after the 2008 - 2009 crisis period; and

3. Suggesting a way to reduce the forecast errors in forecasting future real economic activity based on financial market variables in view of our results. 
Our basic model for forecasting ${ }^{5}$ the future real economic activity is in the form

$$
\Delta y_{t, t+h}^{h}=\beta_{0}+\sum_{i=1}^{l} \beta_{i} \Delta y_{t-i}^{h}+u_{t}
$$

where $\Delta y_{t, t+h}^{h}$ denotes the future $h$-month change in the log value of industrial production index, and $\Delta y_{t, t-i}^{h}$ denotes the lagged values of the change in the log of industrial production index $\left(y_{t}\right)$ for the horizon $h$. Parameters $\beta_{0}$ and $\beta_{i}$ denote the constant and the coefficients on the lagged values, respectively, and $u_{t}$ denotes the error term. In other words, our benchmark forecast model is an area-specific (separately for the euro area and the UK) AR-representation for the future changes in real activity, where the optimal lag length $l$ is determined based on the Akaike and/or Schwarz information criteria. In the spirit of many previous studies, an augmented forecasting model based on financial market information is obtained by adding a set of lagged values of some prominent financial market variables, i.e., the term spread ( $t s)$, short-term interest rate $(r)$ and the stock market excess return ${ }^{6}(e r)$ to the forecasting model, yielding

$$
\Delta y_{t, t+h}^{h}=\beta_{0}+\sum_{i=1}^{l} \beta_{i} \Delta y_{t-i}^{h}+\gamma t s_{t-1}+\delta r_{t-1}+\theta e r_{t-1}+u_{t}
$$

where in addition to the previously defined variables and notations, $\gamma, \delta$ and $\theta$ are the regression parameters on the term spread, short-term interest rate and excess return on stock markets, respectively. Finally, as the main new innovation, the role of economic policy uncertainty in these kinds of forecasting models is examined based on a regression model

$$
\Delta y_{t, t+h}^{h}=\beta_{0}+\sum_{i=1}^{l} \beta_{i} \Delta y_{t-i}^{h}+\gamma t s_{t-1}+\delta r_{t-1}+\theta e r_{t-1}+\lambda_{k} i_{E P U, t-1}^{k}+u_{t},
$$

\footnotetext{
${ }^{5}$ Note that even though our modeling at the forecasting stage follows the idea presented in equation (1), the actual benchmark regression model (and its extensions) for generating dynamic out-of-sample forecasts is always a simple AR-model, where the current $h$ period changes in real activity $y$ at time are regressed on past $h$ period changes in the same variable. Hence, we are not regressing, e.g., future actual $h$-period changes on past $h$ period changes because this regression would have produced much poorer out-of-sample forecasts already for the benchmark ARrepresentation.

${ }^{6}$ Here we follow the previous literature, such as, Campbell and Shiller (1988), Shiller (1991) and Junttila (2007).
} 
where $i_{E P U, t-1}^{k}$ refers to the lagged value of either the log of US, European, or the UK policy index $(k=U S ; E U R ; U K)$, and $\lambda_{k}$ refers to the corresponding regression parameter. Hence, all our testable specifications are nested and dynamic, containing the lagged values of also the added variables in the augmented versions of the basic benchmark AR-representation of the forecasting model.

One of the key interesting research questions in our analyses will concern the role of other than own area's economic policy uncertainty information in using the area-specific financial market information for forecasting the future real economic activity in the euro area and the UK. Special focus will be given to the role of the US EPU index vs. the European index and, in addition, to the role of the UK index in having an effect on forecasting the euro area real activity

\section{Data and empirical results}

\subsection{Descriptive statistics}

Our macroeconomic and financial market data are obtained from the OECD database on Monthly Monetary and Financial Statistics, which is a subset of the OECD Main Economic Indicators (MEI) data ${ }^{7}$. Our samples for both the euro area and UK are from January 1997 to September $2016^{8}$. For the euro area, the financial market data set contains the monthly observations on the long-term (10 years) interest rate (aggregated for 19 countries), short-term (3 months) Euriborrates, and the euro area general stock market price index ${ }^{9}$. For the UK, the short-term interest rate is the 3-month London Interbank Offered rate, and the long-term interest rate is the 10-year government bond yield, whereas the stock price measure is the general price index from the London stock exchange. The real activity measure $(y)$ for both the euro area and the UK is the seasonally adjusted index of industrial production for the 19 euro area countries and for the UK separately. The term spread $(t s)$ is defined conventionally as the difference between the long-term

\footnotetext{
${ }^{7}$ http://stats.oecd.org/Index.aspx?DataSetCode=MEI_FIN\#.

${ }^{8}$ Data for the euro area would have been available already from the beginning of 1994, but because one of our aims in this paper is to discuss and compare the results between the euro area and the UK, we use the same overall sample for both.

${ }^{9}$ Monthly values are based on calculating the arithmetic averages of the closing daily values on the all-share, broad price index.
} 
(10-year) and the short-term (3-month) interest rate, while the excess stock return (er) is defined as the 12-month change in the log of general price index minus the 3-month interest rate. The economic policy uncertainty (EPU) index data are for the aggregate uncertainty index (i.e., not the purely newspaper based version) available for the US, UK and Europe from Www.policyuncertainty.com.

\section{INSERT FIGURES 1 - 8 HERE}

Figures 1 - 4 give the time series graphs for the future $12-m o n t{ }^{10}$ real economic activity in the euro area (i.e., 12-month ahead changes in the log of industrial production index), first, against the contemporaneous values of financial market variables (the euro area term spread, short-term interest rates and the stock market excess returns in Figure 1), and then, against the three analyzed EPU-indexes from Europe (Figure 2), US (Figure 3), and UK (Figure 4). Figures 5 - 8 report the corresponding series for the UK data, for comparison. Table 1 gives the descriptive statistics for both cases. When comparing the euro area data to the UK data, it seems that the rapid real activity slowdown ${ }^{11}$ has started in both areas almost immediately after the stock market collapse at the end of 2008. Furthermore, by simple visual inspection of both the Figures 1 and 5, we see that at least the stock market performance and the term spread clearly might have some explanatory power for the future real economic activity, but the 12-month horizon might not be the optimal one when using the financial market variables in a forecasting model for future macroeconomic activity. Another obvious finding from viewing the graphs is the clear change in the correlation between the short-term interest rate and future real activity after the 2008 crisis, when the central banks started to approach the lower bound of interest rates along with the adoption of their QE programs. Furthermore, when viewing the time series on the three prominent EPU-indexes in forecasting the

\footnotetext{
${ }^{10}$ Corresponding figures for 3-, 6-, 9-, and 24-month horizons are available from the authors upon request.

${ }^{11}$ Remember to read the graphs on the 12-month changes in the log of industrial production as forward looking, so the negative extreme spikes in the figures around January to June 2008 represent actual changes in the January to June 2009 values.
} 
euro area and UK activities, also their role might have changed after the 2008 crisis, but actually they might still be highly relevant at least at the 12-month horizon.

\section{INSERT TABLE 1 HERE}

Descriptive statistics for the case of the 12-month real activity horizon reported in Table 1 confirm some of our first stage eyeball findings from the data. First, for the part of real economic performance, even though the UK real activity has been slightly negative (-0.42\% per annum) and the euro area activity has been positive $(0.73 \%$ per annum) on average, the euro area activity has clearly varied more during the analyzed time period. On the other hand, the euro area interest rate markets have been more stable, whereas the UK stock market has been more stable, even though the monthly average stock market excess return has been clearly negative there ${ }^{12}$. In the euro area, the simple correlation coefficients between the future real economic activity and financial market returns seem to be somewhat higher than in the UK economy. The strongest correlations of all our analyzed variables are among the three EPU-indexes, and the UK EPU-index seems to be more correlated with the European aggregate index than with the US index. Each of the EPU indexes would also seem to be clearly positively correlated with the interest rate spread, and the correlations with the future real activity are actually closer to their correlations with the stock market performance. Note that for our further analyses, at this point, we skipped the short-run interest rate because the zero lower bound era dominates our second sub-sample period. Hence, for the interest rate variables, we will be focusing in our regression analyses only on the role of the term spread, and to be more precise, actually on the slope of the yield curve, as the traditionally defined difference between the 10-year and 3-month interest rates.

According to most of the unit root test results, almost half of the data in our models seem to have behaved like a non-stationary time series during the analyzed time periods. However, the results

\footnotetext{
${ }^{12} \mathrm{We}$ also calculated the sub-sample descriptive statistics for the period before the 2008 crisis and after that and noticed that the role of 2008 crash is enormous in all the financial market values, and it also has changed the correlations between the returns in various financial market sectors. These results (available also upon request) gave us the first stage indication that our forecasting exercise also should absolutely be divided in two, i.e., the pre- and post-2008-crisis sub-samples.
} 
from the ADF and KPSS-tests are, in many cases, in strong contrast to each other ${ }^{13}$ for all the EPUindexes. On the other hand, the test with the null of the unit root (ADF) suggests non-stationarity of both the euro area and the UK term spread variables. Furthermore, the test with the stationarity null (KPSS) supports this inference for the euro area but not for the UK term spread. These results suggest that some of the variables in our data set should be differenced for further analyses, and some should not. However, due to the somewhat vague and contradictory results from the unit root tests, our final conclusion for the next step of analyses was based also on using the results from the Zivot and Andrews (1992) test that allows for a single break in the intercept, the trend or both, in the data generating processes of the analyzed time series in unit root testing. The results from the Zivot and Andrews-test (denoted Z-A in Table 1) confirm our previous finding that the latest macroeconomic and financial market crash indeed has had significant effects on the time series analyzed here, but we might be able to treat most of them as stationary processes for our further analyses if we take the structural changes that have clearly emerged approximately since the end of 2008 into account in our analysis ${ }^{14}$.

In view of preliminary results discussed above, first of all, the role of the traditional forecasting variables from the financial markets might prove to be strong in our out-of-sample forecasting exercise for the euro area and the UK. Furthermore, as a novel application, we will examine the role of the EPU-indexes in forecasting the future real economic activity, so the next stage of our analysis was to do the actual forecasting exercises.

\footnotetext{
${ }^{13}$ For example, the results from the tests with the null of the unit root suggest stationarity in all cases, and for the case with the null of stationarity, they indicate non-stationarity for each and every EPU index, and vice versa for the change in the future real activity at the 12-month horizon in the euro area.

${ }^{14}$ Even after controlling for the possibilities of structural changes in the unit root test, the stock market excess return in the euro area and the UK real activity, term spread and stock market excess return seemed to behave like nonstationary processes. Furthermore, the Zivot \& Andrews test did not reject the non-stationarity of the euro area or the UK excess stock returns either, but the break points seemed to be somewhat different for these two series compared to other data. Hence, in terms of avoiding spurious regressions for these variables, we had to also consider forecasting models that would use differenced values of them. Complete results for these versions are available from the authors upon request, but in terms of forecasting performance, they proved not to be more useful than the models reported in the next section.
} 


\subsection{Regression results of the forecasting models}

\subsubsection{Results for the euro area}

Tables 2 and 3 report the empirical results from the OLS-regressions of the forecasting models (1)

- (3) given in section 2.3 for the euro area and the UK, respectively. The first column in both tables reports the results for the benchmark AR-representation ${ }^{15}$ for the real economic activity (Model 1). The second column reports the AR-model augmented by the financial market variables (Model 2), whereas columns 3 - 5 report the model in which the augmentation includes the economic policy uncertainty (EPU) index, (Model 3) and finally, columns 6 - 8 report the results from the AR-model augmented by only the individual EPU-indexes, one by one. To be able to reveal the possibly varying effects of the policy uncertainty from the US, Europe, and the UK, we introduce each of the EPU indexes from these areas separately to our analysis in columns 3 - 8 . The separate reporting of results from using each of the EPU indexes is based on the observed strong correlation between the indexes that was reported in Table 1.

To allow for the possibility of time-varying parameter estimates, especially in terms of the effects of the Great Recession after 2008, in our final forecasting exercises, we will use a rolling regression approach with a 5-year moving window and we will discuss the results regarding only the 12-month horizon ${ }^{16}$. In addition, as was witnessed by the sub-sample descriptive statistics and by the unit root test results, we specifically want to make a clear distinction between the subperiods before the 2008 crisis and the periods after that. For that purpose, in Tables 2 and 3, we also report the starting values for the rolling regressions separately for both these sub-periods

\footnotetext{
${ }^{15}$ According to the Schwarz and Akaike information criteria, an AR(1) model was suggested as the best benchmark model for both the euro area and UK data and for the sample prior to the latest crisis and after that. However, in some cases, the Akaike criterion suggested much longer lag lengths, such as 9 for the euro area data prior to the latest financial crisis. Hence, for the sake of robustness, we performed the forecasting exercises also using these longer lag structures, but in terms of the out-of-sample forecasting performance, the longer AR-presentations proved not to be superior to the simple AR(1)-presentation. All the results on our robustness checks are available from the authors upon request.

${ }^{16}$ The five-year moving window was utilized in all the out-of-sample forecasting exercises based on the fact that many financial market practitioners use the previous 60 months data in their forecasting and performance analyses (see for example Griffin, 2002). The rolling five-year estimation procedure uses the first 60 observations as the starting sample, and the first out-of-sample forecasts are formed based on these parameter estimates and a dynamic forecasting procedure for generating the later forecasts. Then, one observation is added to the end of sample for each variable in the regression, whereas the first observation from the beginning is dropped, keeping the sample size as 60 as before. This procedure is repeated until all the observations are utilized.
} 
(panel a, and panel b), but for the sake of brevity, we only report values for the 12-month forecast horizon $^{17}$. Analogously to many studies on the Great Recession since 2008, for both the euro area and the UK data, we chose the Lehman Brothers bankruptcy in September 2008 to represent the final starting point of the global distress in financial markets and real economies, so that will be the sample break-point also for our forecasting exercises.

\section{INSERT TABLE 2 HERE}

From Table 2, we see that at least in the euro area data, the simplest possible AR-model for our out-of-sample forecasting exercise does not work very well in terms of its forecasting performance, even though the AR-parameter is always statistically significant in the regression model. For the interpretation of the parameter estimates, our main focus is in the additional variables. For their part, it seems that the introduction of financial market variables is already highly relevant from the point of view of the statistical significance of the individual parameters estimated for the augmentation variables. Analogous to findings in other studies, e.g., Duarte et al (2005), in the euro area data for the forecasting period before the financial crisis, the term spread always has a positive and statistically significant coefficient, which is also economically clearly significant. The numerical value of it implies that as the term spread ${ }^{18}$ increases by one percentage point, it has a positive effect on changes in real economic activity, and the effect varies from a 0.37 to a 0.54 percentage points rise, depending on the model. This is a clearly economically significant relationship. In most of the previous papers, the slope of the yield curve has also been noted to be positively connected to the future real economic activity, even though recent studies have also revealed that the predictive power of the yield curve slope fluctuates over time (see Stock and Watson, 2003, Estrella et al., 2003, Mody and Taylor, 2003, Rossi and Sekhposyan,

\footnotetext{
${ }^{17}$ All the results for all the other (3, 6, 9 and 24 months) forecast horizons are available upon request from the authors.

${ }^{18}$ As already mentioned, to be exact, we actually use the slope of the yield curve as a regressor in our model because we are using the difference between the 10-year and 3-month interest rates, which has been used most intensively (and successfully) in the previous literature on the ability of the components in the term structure of interest rates in forecasting future real economic activity. A recent analysis of the prominent role of other factors in the yield curve (i.e., the level and curvature of the curve) for forecasting future macro economy has been given, e.g., in Chauvet and Senyuz (2016), in which they also give a comprehensive literature review on the previous studies on the forecasting ability of the term structure of interest rates.
} 
2011, and Hännikäinen, 2016). These results indicate that also in our analysis, the presumption is that everything should be analyzed allowing for the time-variation in the regression coefficients of the models.

For the role of the interest rate markets, our results at this stage also support the earlier findings of e.g., Giacomini and Rossi (2006) and Bordo and Haubrich (2004, 2008a, 2008b) on the close connection between the slope of the yield curve and monetary policy in terms of forecasting future real activity. Giacomini and Rossi (2006) have argued that in the US, changes in the predictive content of the yield curve are connected to changes in the monetary policy of the central bank. On the other hand, Bordo and Haubrich found in all their abovementioned studies that the credibility of the monetary policy affects the predictive power of the yield curve, i.e., the slope of the yield curve forecasts well the future output growth when inflation is highly persistent.

For reflecting the stock market effects contained in the euro area data, our results are clearly different. The excess stock market return does not seem to be a relevant factor for explaining changes in real activity at all during the forecasting period before the financial crisis. However, when comparing the results from the two sub-periods in the euro area data, our findings regarding the role of stock market performance in forecasting the future real economic activity seem to be clearly different. A priori, based on earlier empirical findings (see for example Stock and Watson, 2003; Kuosmanen et al, 2015; Junttila and Korhonen, 2011) and on the theoretical ideas in the Gordon (1962) dividend pricing model and the Cochrane (2006) discount factor analysis, future real economic activity should be positively related to the current valuation of common stocks. Hence, rising excess returns in the past should imply positive prospects for the future real economic performance. According to our results reported in Table 2, this a priori relationship would clearly seem to hold for the euro area data in the starting regressions especailly for forecasting the future real activity during and after the financial crisis. Furthermore, Economic Policy Uncertainty would seem to have a very strong role prior to the crisis, in the model in which the financial variables are involved, and both in-sample and out-of-sample terms. In fact, using solely any of the individual policy uncertainty measures would seem to always produce better out-of-sample forecasts than the FV model does but only during the normal (or rising) economic situation, i.e., prior to the financial crisis (see panel a in Table 2). Actually, the model containing 
only the European uncertainty index produces the best out-of-sample forecast statistics for that sub-period.

However, for the models regarding forecasting real activity during the financial crisis period (panel b in Table 2), the situation changes completely. First, the coefficient on the term spread variable is always negative and statistically strongly significant. Remembering that the zero interest rate era dominates in this sub-sample, our results seem to suggest that the slope of the yield curve has implicitly adopted the role of short-term interest rate as a monetary policy instrument in terms of its effects on real economic activity during and after the financial crisis period. According to our results, during the crisis period, the increasing values of the slope of the yield curve have had a tightening effect on future real economic activity. Furthermore, the stock market performance during that period has obtained a positive role in affecting the real economic activity, and, as mentioned before, this is also theoretically and intuitively a meaningful result. On the other hand, the introduction of EPU variables to the forecasting model does not have effects on the role of stock market information regarding the future real activity. The EPU parameter estimates are not statistically significant in the model containing the financial variables, but when used as a single individual explanatory variable, their coefficients are negative and statistically significant at least at a $5 \%$ risk level. However, the models involving only the individual EPU-indexes have the worst out-of-sample forecast performance, so our results highlight the obviously important role of financial variables in forecasting the real economic activity, especially for the period during and after the financial crisis in the euro area. It also seems

obvious that the policy uncertainty indexes might contain similar information contents as contained in the financial variables analyzed here, but clearly, the best forecasting model is obtained by using only the financial variables as additional information to the benchmark ARmodel.

\subsubsection{Results for the $U K$}

Viewing the results for the UK data are similar to looking at the other side of the coin completely. First, the term spread variable does not seem to have any kind of role in explaining the changes in future real activity during either of the sub-periods. Additionally, the effects of policy uncertainty are perhaps a bit weaker in the UK data, even though as a single explanatory variable added to the 
AR benchmark model they would seem to produce the best out-of-sample performance before the financial crisis (see panel a in Table 3). However, in the in-sample comparison, compared to the term structure, a more important variable affecting the real economic activity would seem to be the stock market performance. Its parameter estimate is positive and statistically significant at a $1 \%$ risk level in every specification in which it is included, and the inclusion of the EPU- index has only a marginal role on its effect, in every case. This overall result seems to also hold in the data after the financial crisis, but the statistical significances are clearly smaller in those data. From the individual EPU effects, the US policy uncertainty seems to have had the economically strongest and statistically also the most significant role for the UK real activity prior to the crisis period, but during the crisis period, the role of European economic policy uncertainty seems to have increased both economically and statistically. In cases in which the coefficients on policy uncertainty variables are statistically significant at least at the $10 \%$ level, their sign is also intuitively right, i.e., negative. According to our results, at least partly due to the lower variation in the real economic activity in the overall sample, the out-of-sample forecast statistics are clearly better in the data from the UK compared to the euro area data, both before and after the crisis. In 6 out of 7 cases, the out-of-sample forecast statistics are better for the augmented model compared to the benchmark AR-model during the crisis period but they are better in only 2 out of 7 cases before the crisis.

All these results call for more detailed analysis of the connections between the financial market returns and economic policy uncertainty measures. It seems that the 2008 crisis has strongly changed the interconnections of these variables, and the changes might also be completely different in different markets, countries, and forecast horizons. Furthermore, the results reported for the 12-month horizon regarding our starting regressions speak in favor of the overall conclusion that the forecasting exercises for future real economic activity containing financial market and economic policy uncertainty variables should absolutely be conducted using estimation methods enabling time-varying coefficients in the forecasting models.

INSERT TABLE 3 HERE 


\section{Conclusions}

Our empirical analysis on the role of the Economic Policy Uncertainty (EPU) effects in forecasting the future real economic activity in the euro area and in the UK before and after the 2008 global economic recession indicates that the policy uncertainty seems to be somewhat connected to the financial market variables. The inclusion of the EPU measures from the US, the UK, and Europe as a whole does have an effect on the out-of-sample predictive power of a forecasting model that uses a set of standard, well-known indicator variables from the financial markets to forecast the future changes in the index of industrial production in the euro area and in the UK. In particular, the forecasting power of excess stock market returns seems to be very sensitive to the inclusion of the policy uncertainty measures. Furthermore, the out-of-sample forecasting power seems to vary a lot depending on which of the three prominent policy uncertainty measures is included to the forecasting model.

According to our results, the June 2016 Brexit referendum result in favor of British exit from the European Union is something that will have an effect also on forecasting the future real economic activity in the euro area, especially in the longer run, because it increased the UK EPU index value dramatically some weeks prior to the referendum. However, our results do not actually indicate that it is necessarily bad news for the euro area because one of the main channels through which the increasing economic policy uncertainty in the UK (and Europe, too) seems to affect the future real economic activity in the euro area is the financial market channel, and on the other hand, during the era of massive QE operations, the role of the financial market channel itself has clearly changed in terms of its effects on future real economic activity. Hence, it is absolutely vital to analyze the prominent effects of the Brexit on the future economic performance of the euro area and Europe as a whole through finding more evidence on the true financial market effects of the Brexit or any other similar kind of political, more or less exogenous shock affecting the performance of the various sectors of financial markets. This will also be the next step in our analyses. 


\section{References}

Aron, J., Duca, J., V., Muellbauer, J., Murata, K., Murphy, A., 2012. Credit, housing collateral, and consumption: Evidence from Japan, the UK, and the US. Review of Income and Wealth $58: 3,397-423$.

Baker, S. R., Bloom, N., Canes-Wrone, B., Davis, Rodden, J., 2014. Why has US policy uncertainty risen since 1960? American Economic Review, Papers and Proceedings 104/5, 56-60.

Baker, S. R., Bloom, N., Davis, S.J., 2016. Measuring Economic Policy Uncertainty. Quarterly Journal of Economics 131 (4), 1593-1636. 2015. What triggers stock market jumps? Paper presented at the 2015

ASSA Meetings.

Basset, W. F., Chsak, M., B., Driscoll, J., C., Zakraj E. K., 2014. Changes in bank lending standards and the macroeconomy. Journal of Monetary Economics 62, 23-42.

Bluedorn, J., C., Decressin, J., Terrones, M. E., 2016. Do asset price drops foreshadow recessions? International Journal of Forecasting 32, 518-526.

Bordo, M., D., Duca, J., V., Koch, C., 2016. Economic Policy Uncertainty and the Credit Channel: Aggregate and Bank Level U.S. Evidence Over Several Decades. NBER Working Paper 22021.

Bordo, M., D., Haubrich, J. G., 2004. The yield curve, recessions and the credibility of the monetary regime: Long-run evidence 1875-1997. NBER Working Paper 10431.

, 2008a. The yield curve as a predictor of growth: Long-run evidence, 1875-1997. The Review of Economics and Statistics 90(1), 182-185.

,2008b. Forecasting with the yield curve; Level, slope, and output

1875-1997. Economics Letters 99, 48-50. 
Campbell, J.Y.,1991. A variance decomposition for stock returns. Economic Journal, 101, 157179.

Campbell, J.Y., Shiller, R.J. 1987. Stock prices, earnings, and expected dividends. Journal of Finance, XLIII (3), 661-676.

Chang, T., Chen, W.-Y., Gupta, R., Nguyen, D.K., 2015. Are stock prices related to the political uncertainty index in OECD countries? Evidence from the bootstrap panel causality test. Economic Systems 39, 288-300.

Chauvet, M., Senyuz, Z., 2016. A dynamic factor model of the yield curve components as a predictor of the economy. International Journal of Forecasting 32, 324-343

Cochrane J., 2006. Financial markets and the real economy. Edward Elgar, Cheltenham.

Colombo, V., 2013. Economic policy uncertainty in the US: Does it matter for the Euro area? Economics Letters 121, 39-42.

Davis, S. J., 2016. An Index of Global Economic Policy Uncertainty. NBER Working paper 22740.

Drechsel, K., Scheufele, R., 2012. The performance of short-term forecasts of the German economy before and during the 2008/2009 recession, International Journal of Forecasting $28,428-445$.

Duarte, A., Venetis, I.,A., Paya, I., 2005. Predicting real growth and the probability of recession in the Euro area using the yield curve. International Journal of Forecasting 21, 261-277.

Estrella, A., Rodrigues, A., P., Schich, S., 2003. How stable is the predictive power of the yield curve? Evidence from Germany and the United States. Review of Economics and Statistics $85,629-644$.

Federal Open Market Committee, 2009. Minutes of the December 2009 Meeting, http://www.federalreserve.gov/monetarypolicy/fomcminutes20091216.html. 
Ferrara, L., Marsilli, C., Ortega, J.-P., 2014. Forecasting growth during the Great Recession: is financial volatility the missing ingredient? Economic Modelling 36, 44-50.

Giacomini, R., Rossi, B., 2006. How stable is the forecasting performance of the yield curve for output growth? Oxford Bulletin of Economics and Statistics 68, 783-795.

Gordon, M., J., 1962. The investment, financing, and valuation of the corporation. Irwin Homewood, Illinois.

Hännikäinen, J., 2016. When does the yield curve contain predictive power: Evidence from a datarich environment? MPRA Paper No. 70489.

International Monetary Fund, 2012. World Economic Outlook: Coping with High Debt and Sluggish Growth, October, IMF Press.

, 2013. World Economic Outlook: Hopes, Realities, Risks, April, IMF Press.

Junttila, J., 2007. Forecasting the macroeconomy with contemporaneous financial market information: Europe and the United States. Review of Financial Economics, 16 (2), 149-175.

Junttila, J., Korhonen, M., 2011. Utilizing financial market information in forecasting real growth, inflation and real exchange rate. International Review of Economics and Finance 20, 281301.

Jurado, K., Ludvigson, S., C., Ng, S., 2015. Measuring Uncertainty. American Economic Review 105(3), 1177-1216.

Karnizova, L., Li, J., 2014. Economic policy uncertainty, financial markets and the probability of US recessions. Economics Letters 125, 261-265.

Kuosmanen, P., Nabulsi, N., Vataja, J., 2015. Financial variables and economic activity in the Nordic countries. International Review of Economics and Finance 37, 368-379.

Li, X.-M., Zhang, B., Gao, R., 2015. Economic policy uncertainty shocks and stock-bond correlations. Economics Letters 132, 91-96. 
Ludvigson, S. C., Ma, S., Ng, S., 2016. Uncertainty and Business Cycles: Exogenous Impulse or Endogenous Response? NBER Working Paper No. 21803.

Mody, A., Taylor, M. P., 2003. The high-yield spread as a predictor of real economic activity: evidence of a financial accelerator for the United States. IMF Staff Papers 50, 373-402.

Rossi, B., Sekhposyan, T., 2011. Have economic models forecasting performance for US output growth and inflation changed over time, and when? International Journal of Forecasting 26, 808-835.

Stock, J. H., Watson, M. W., 2003. Forecasting output and inflation: the role of asset prices. Journal of Economic Literature Vol XLI, 788- 829.

Stockhammar, P., Österholm, P., 2016. Effects of US policy uncertainty on Swedish GDP growth. Empirical Economics 50, 443-462.

Wu, J., C., Xia, F., D., 2016. Measuring the macroeconomic impact of monetary policy at the zero lower bound. Journal of Money, Credit and Banking 48/2-3, 253-291.

Zivot, E., Andrews, K., 1992. Further evidence on the Great Crash, the oil price shock, and the unit-root hypothesis. Journal of Business and Economic Statistics 10, 251-70. 


\section{Table 1}

\section{Descriptive statistics}

\begin{tabular}{|c|c|c|c|c|c|c|c|c|c|}
\hline \multirow{2}{*}{$\begin{array}{c}\text { Area } \\
\text { Stat/Var }\end{array}$} & \multicolumn{3}{|c|}{ Euro } & \multicolumn{3}{|c|}{ UK } & \multicolumn{3}{|c|}{ EPU-indexes } \\
\hline & $\Delta y_{t+h}^{h}$ & $t s$ & $e r$ & $\Delta y_{t+h}^{h}$ & ts & $e r$ & $\overline{i_{E P U}^{U S}}$ & $i_{E P U}^{E U R}$ & $\overline{i_{E P U}^{U K}}$ \\
\hline Mean & 0.73 & 1.58 & 0.20 & -0.42 & 0.58 & -1.75 & 4.62 & 4.80 & 5.76 \\
\hline Stdev & 5.16 & 0.98 & 23.47 & 2.98 & 1.34 & 15.58 & 0.37 & 0.41 & 0.68 \\
\hline Min & -24.23 & -0.70 & -67.08 & -12.02 & -2.23 & -49.43 & 3.80 & 3.86 & 3.23 \\
\hline Max & 9.02 & 3.51 & 40.89 & 5.50 & 3.50 & 39.60 & 5.65 & 6.07 & 7.04 \\
\hline $\mathrm{N}$ & 225 & 237 & 225 & 225 & 237 & 225 & 237 & 237 & 237 \\
\hline \multicolumn{10}{|l|}{ Corr } \\
\hline$\Delta y_{t+h}^{h}$ & 1.00 & 0.48 & 0.28 & 1.00 & 0.31 & 0.21 & & & \\
\hline ts & & 1.00 & 0.08 & & 1.00 & 0.14 & & & \\
\hline er & & & 1.00 & & & 1.00 & & & \\
\hline$i_{E P U}^{U S}$ & -0.21 & 0.22 & -0.51 & -0.10 & 0.30 & -0.40 & 1.00 & 0.75 & 0.64 \\
\hline$i_{E P U}^{E U R}$ & -0.12 & 0.42 & -0.33 & -0.02 & 0.50 & -0.16 & & 1.00 & 0.88 \\
\hline$i_{E P U}^{U K}$ & -0.16 & 0.41 & -0.28 & -0.02 & 0.57 & -0.08 & & & 1.00 \\
\hline \multicolumn{10}{|l|}{ UR } \\
\hline $\mathrm{ADF}$ & $--4.66 * * *$ & -2.35 & $-2.59 *$ & $-3.50 * * *$ & -1.98 & $-3.13 * *$ & $-5.91 * * *$ & $-4.60 * * *$ & $-3.49 * * *$ \\
\hline KPSS & 0.23 & $0.76^{* * *}$ & 0.30 & 0.24 & -1.89 & 0.27 & $0.76 * * *$ & $2.33 * * *$ & $3.36 * * *$ \\
\hline \multirow[t]{2}{*}{$\mathrm{Z}-\mathrm{A}$} & $-5.26 * *$ & $-4.96 * *$ & -3.54 & -4.46 & -4.50 & -3.78 & $-7.05 * * *$ & $-7.14 * * *$ & $-5.23 * * *$ \\
\hline & $(2008: 5)$ & $(2008: 11)$ & $(2008: 9)$ & (2009:10) & $(2008: 11)$ & $(2009: 6)$ & $(2007: 8)$ & $(2003: 5)$ & $(2007: 8)$ \\
\hline
\end{tabular}

Notes: Table 1 presents sample means, standard deviations, minimum and maximum values, and the number of observations (N) in the upper panel, and the simple

Pearson correlation coefficients between the analyzed variables in the middle panel. All the statistics are based on monthly observations from the period of $1997: 1-$ 
2016:9. For the real activity data we report only the statistics for the 12-month forecast horizon as an example, so the effective sample ends at 2015:9 for both the cases of euro area and the UK data. In the lowest panel we report the results from augmented Dickey-Fuller tests (ADF, $\mathrm{H}_{0}$ : unit root), Kwiatkowski-Phillips-Schmidt-Shintests (KPSS, $\mathrm{H}_{0}$ : stationarity) and the Zivot \& Andrews-tests (Z-A) allowing for possible break point in the DGP of the time series when testing for the unit roots (break point given in parentheses). The significance levels for all the test statistics are denoted by $*=10 \%, * *=5 \%$, and $* * *=1 \%$. The optimal lag length in the unit root test procedures was based on using the AIC and BIC values. The variables are: $\Delta y_{t+h}^{h}=$ actual 12-month lead (future) value of the 12-month change in the log of industrial production $(\%), t s=$ term spread, i.e. the difference between the 10-year and 3-month nominal interest rate $(\%)$, er $=$ excess stock market return (annualized, 12 -month change in the log of aggregate price index minus the 3-month nominal interest rate, $\%), i_{E P U}^{k}=\log$ value of the Economic Policy Uncertainty indexes for the US, Europe (as a whole) or the UK ( $k=$ US, EUR, UK), respectively. The data sources are OECD/MEI and www.policyuncertainty.com. Note that all the other statistics for the real activity variable $\Delta y_{t+h}^{h}$ are calculated for the actual future 12-month change in the index value, but the unit root tests are for the 12-month change in the log of industrial production index $(\%)$, because our benchmark AR-model uses this variable for the out-of-sample forecast exercise. This corresponds to the calculation process of the annualized stock market excess returns, too. 


\section{Table 2}

Results from the AR-benchmark and augmented forecast regression models for the 12-month horizon; euro area

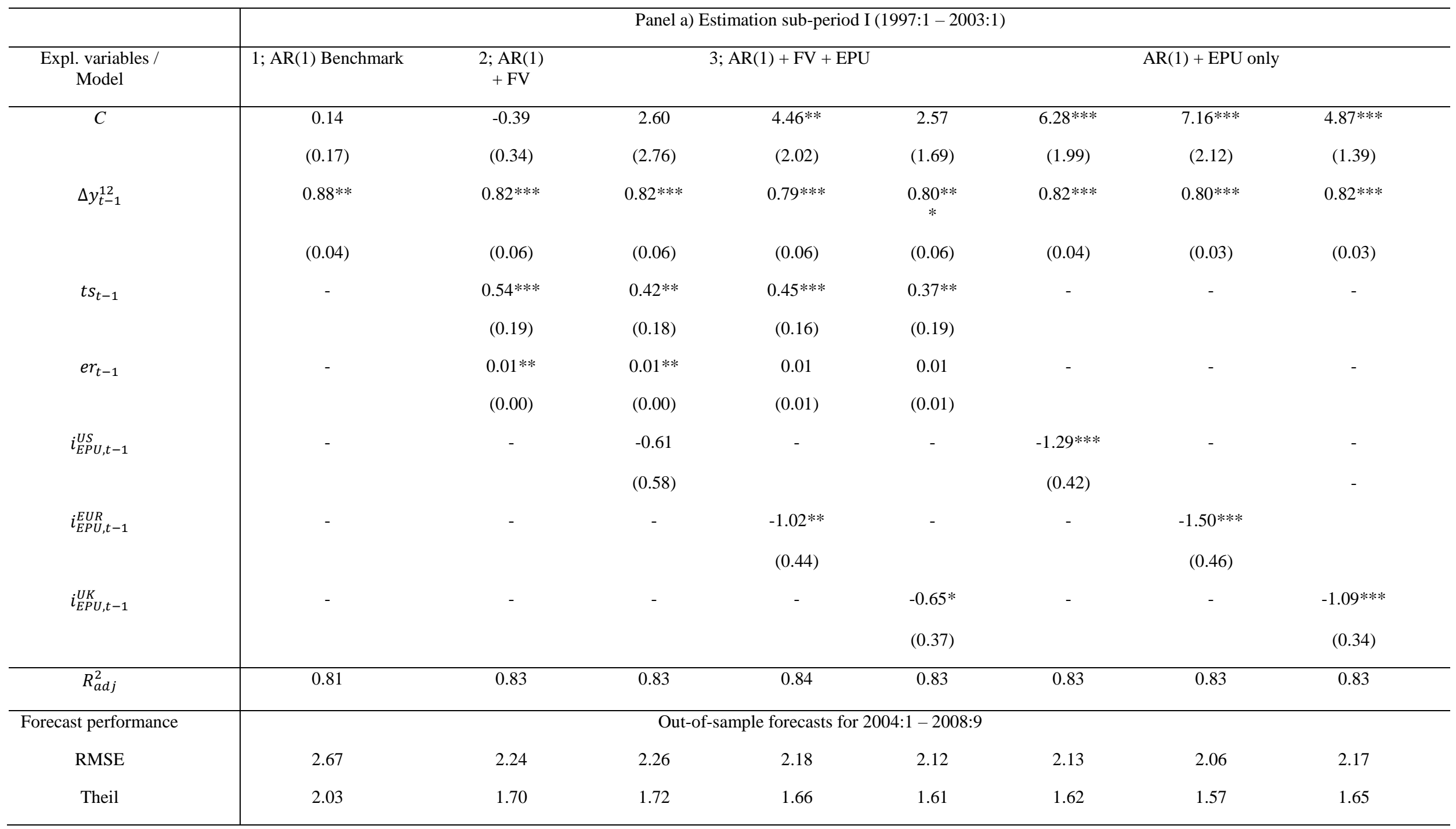




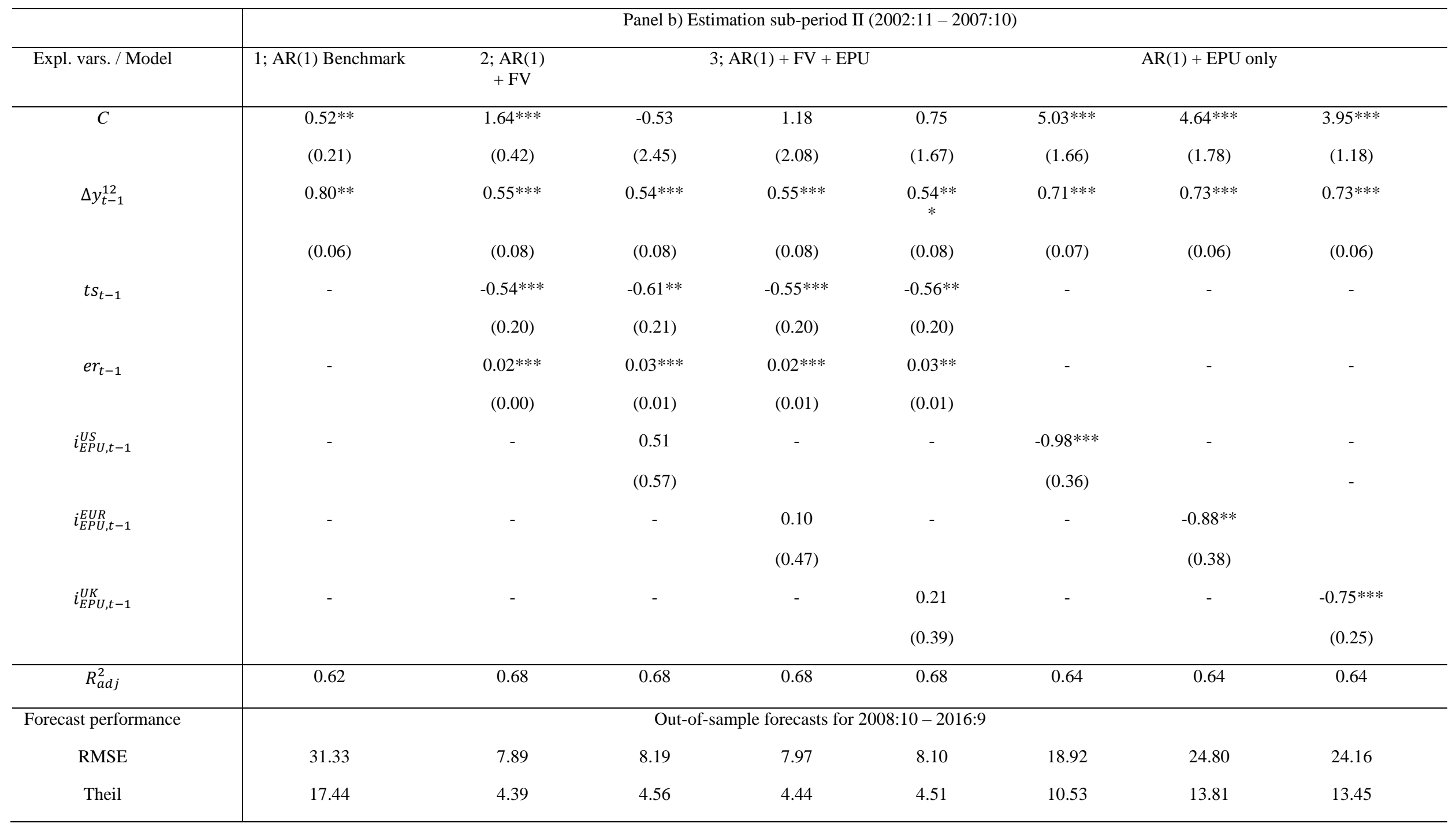

Notes: Table 2 reports the regression parameters (with Newey-West/Bartlett-type HAC standard errors in parentheses) from the OLS-estimation of the starting regressions for forecasting the future real economic activity in the euro area at 12-month horizon with rolling 5-year regression. Division of the analysis into two sub-periods is based on the potential break in the out-of-sample forecasting performance of the models due to the Lehman Brothers collapse in September 2008. The significance levels of the 
parameter estimates are denoted by $*=10 \%, * *=5 \%$, and $* * *=1 \%$. The dependent variable is the 12 -month change in the log of industrial production $(\%)$ at time $t$. $C$ $=$ constant in the regression, $\Delta y_{t-1}^{12}=$ lagged value of the 12-month change in the log of industrial production $(\%), t s_{t-1}=$ lagged value of the term spread, $e r_{\mathrm{t}-1}=$ lagged value of the excess stock market return $(\%), i_{E P U, t-1}^{k}=$ lagged value of the log of Economic Policy Uncertainty index for the US, Europe (as a whole), or the UK $(k=\mathrm{US}$, EUR, UK), respectively. FV denotes the set of financial variables ( $t s, e r)$ and EPU the Economic Policy Uncertainty index. Effects of each of the three different indexes are analyzed separately. $R_{a d j}^{2}$ denotes the adjusted coefficient of determination, RMSE = root mean squared error from forecasting the future values of real activity for the given out-of-sample forecasting period using a 5-year rolling regression procedure. Theil denotes the Theil U-statistics for comparing the RMSE values of the forecasts from the model in question to the RMSE of the "no change" forecast. 


\section{Table 3}

Results from the AR-benchmark and augmented forecast regression models for the 12-month horizon; the UK

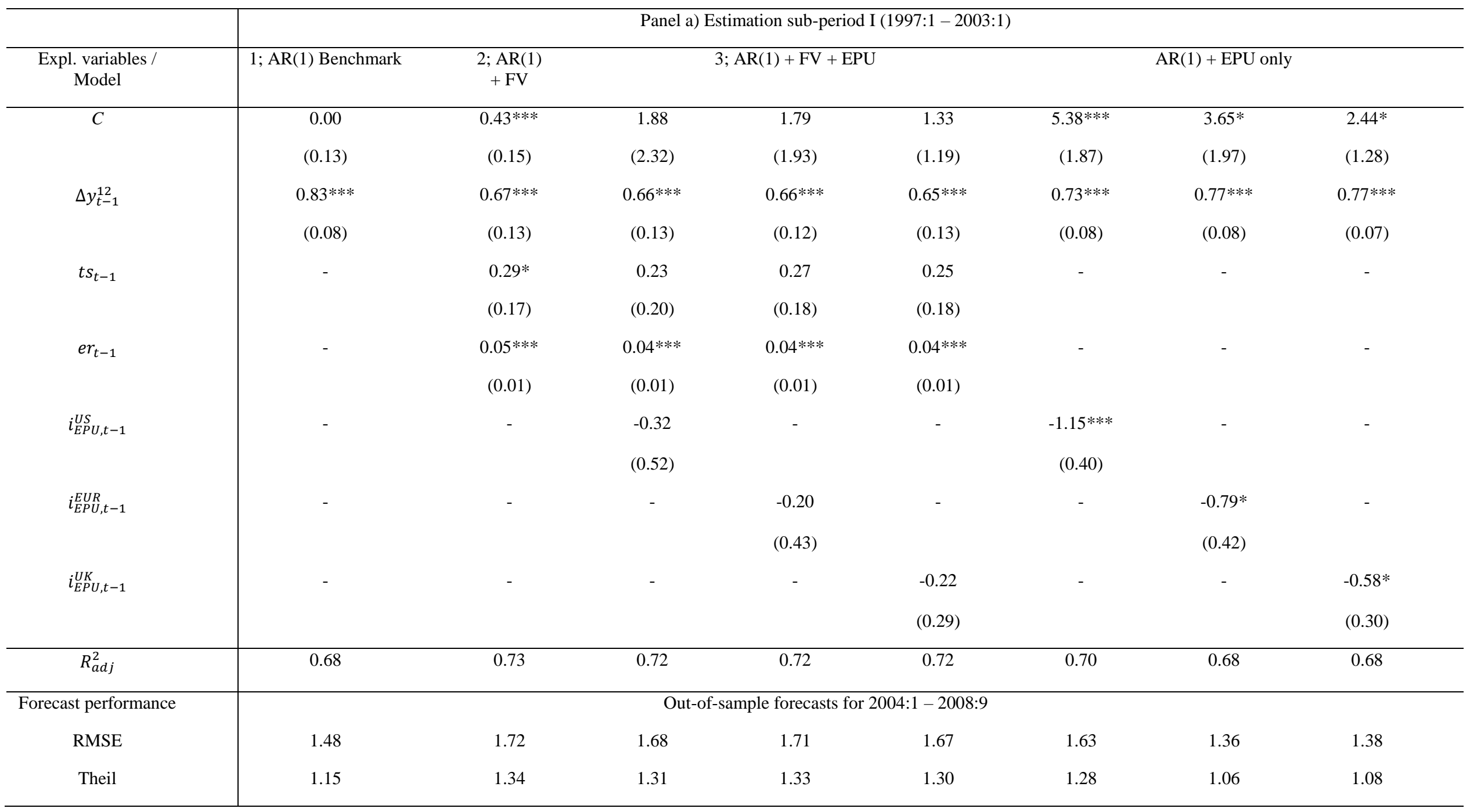




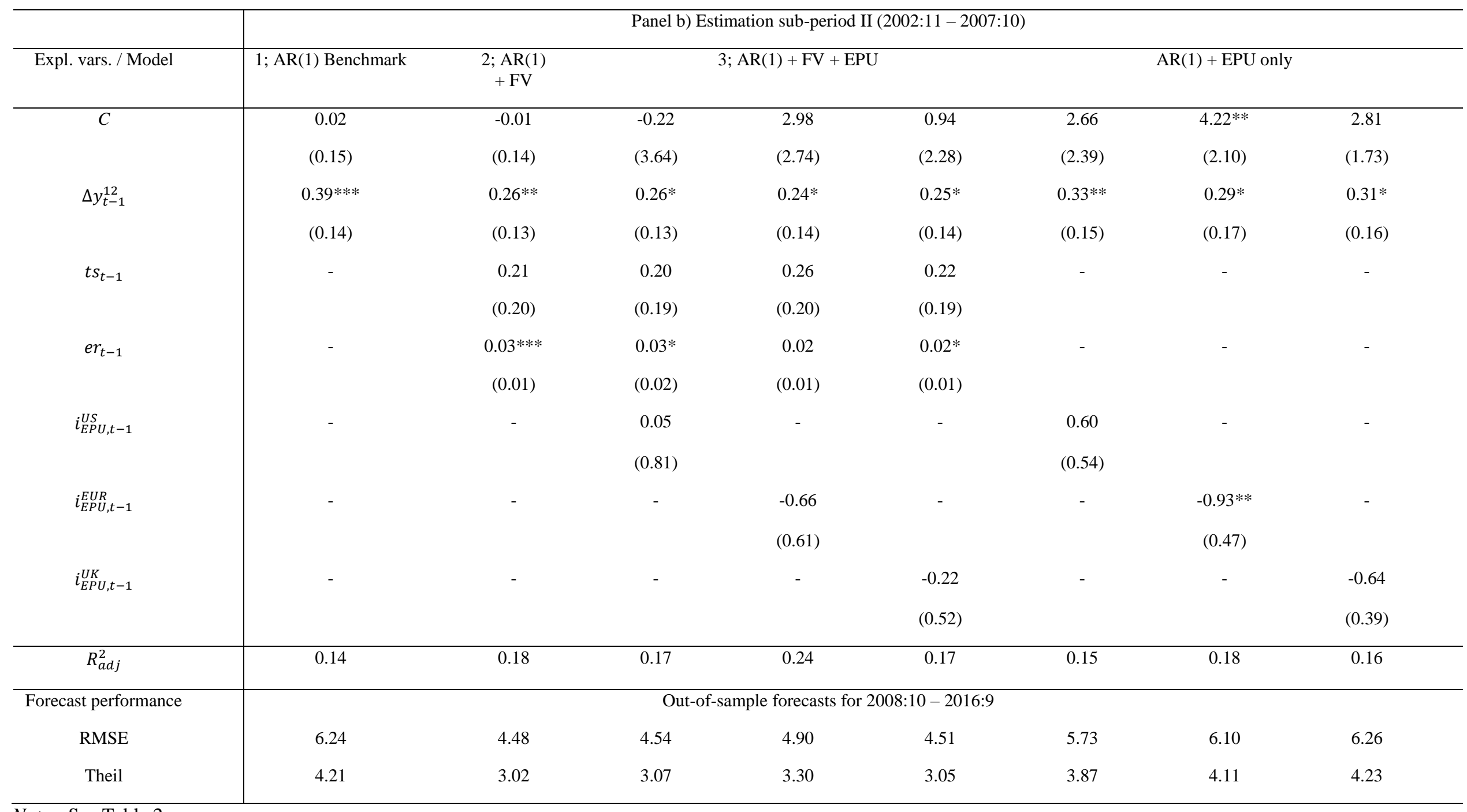

Notes: See Table 2. 


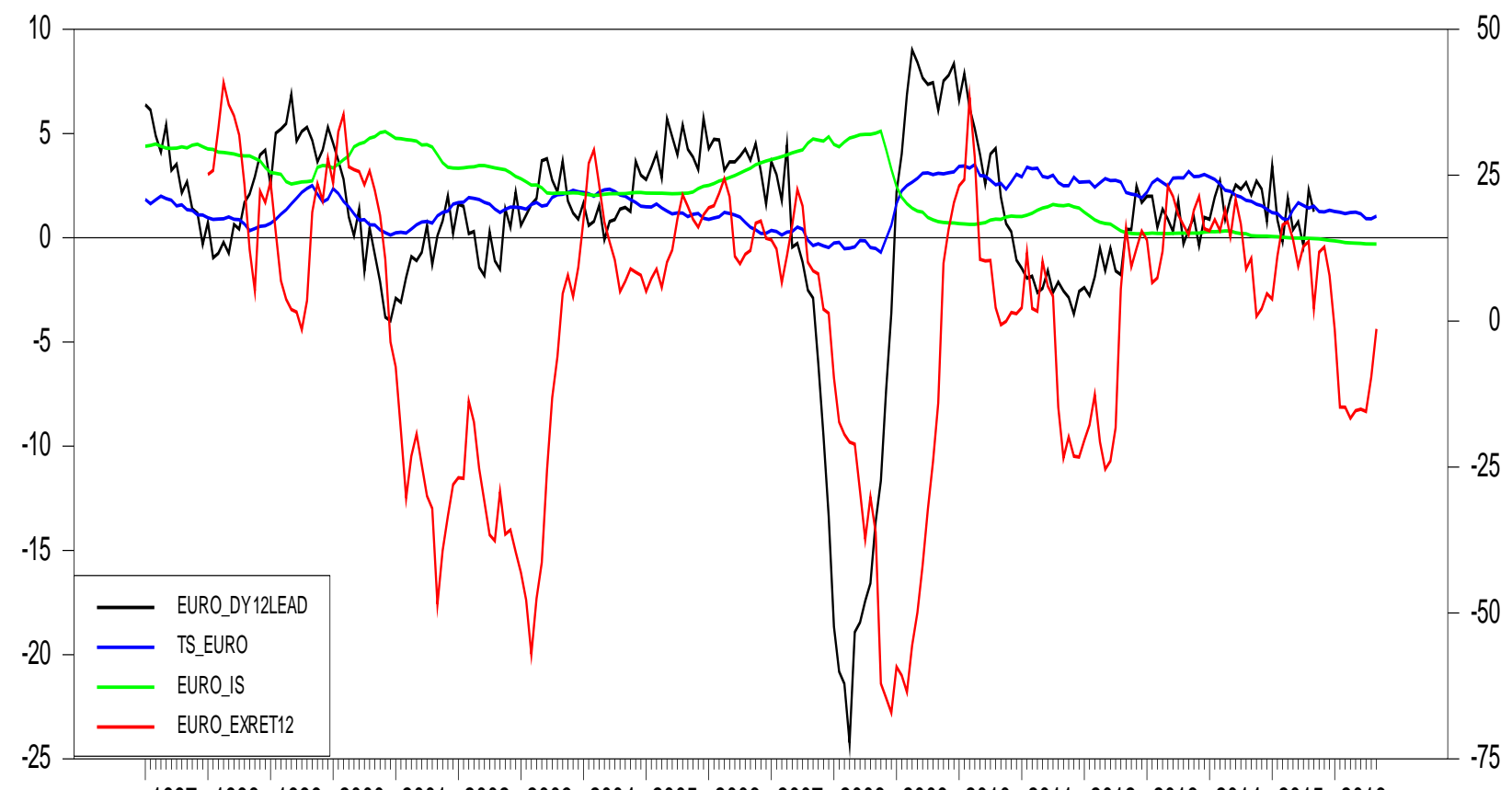

19971998199920002001200220032004200520062007200820092010201120122013201420152016

Fig. 1. Future 12-month change in the real economic activity (EURO_DY12LEAD, left scale), short-term (3month) interest rate (EURO_IS, left scale), the term spread (TS_EURO, left scale) , and aggregate excess return on stock markets in the euro area (EURO_EXRET12, right scale).

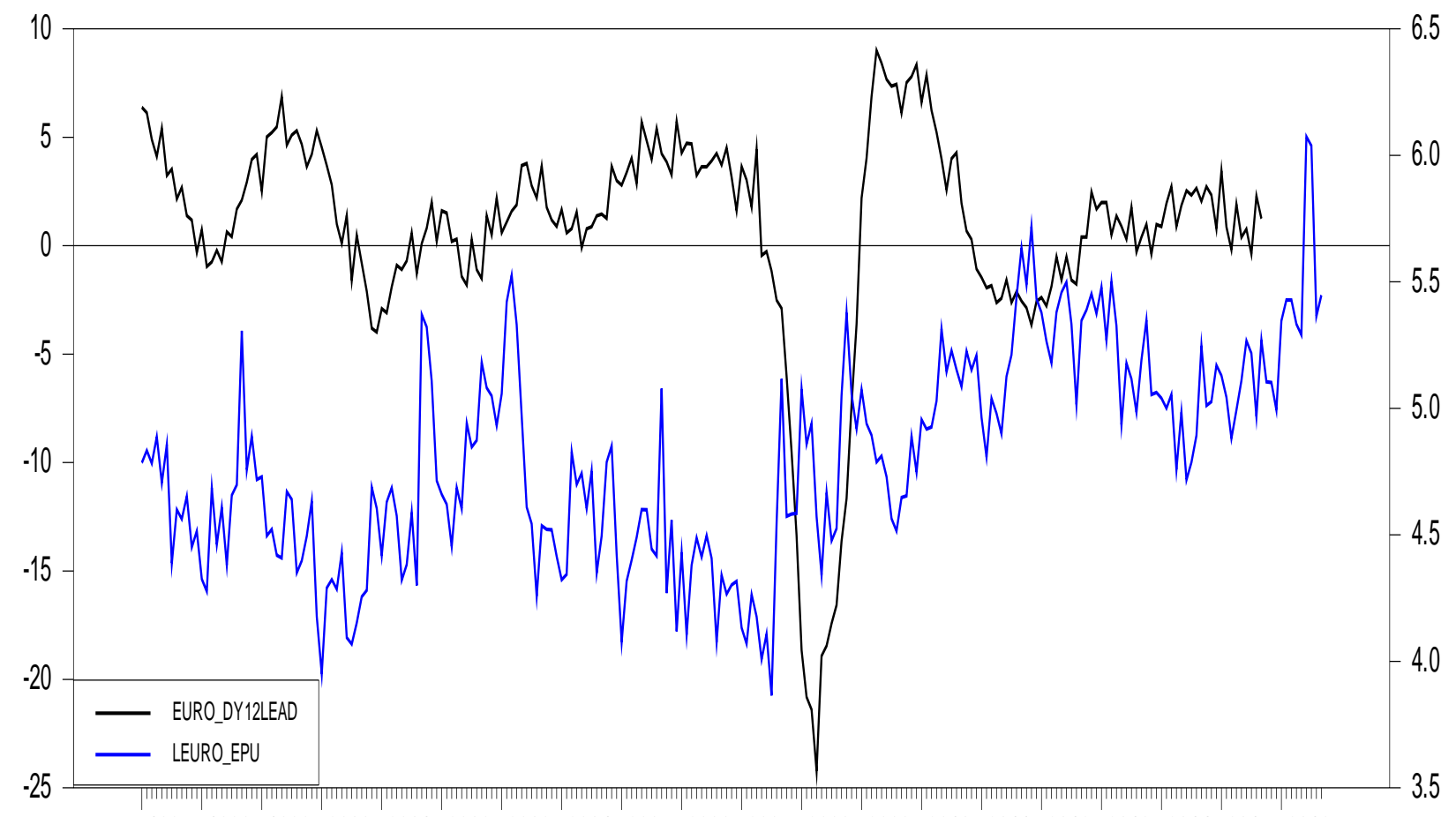

19971998199920002001200220032004200520062007200820092010201120122013201420152016

Fig. 2. Future 12-month change in the euro area real economic activity (EURO_DY12LEAD, left scale) and current values of the log of European Economic Policy Uncertainty index (LEURO_EPU, right scale). 


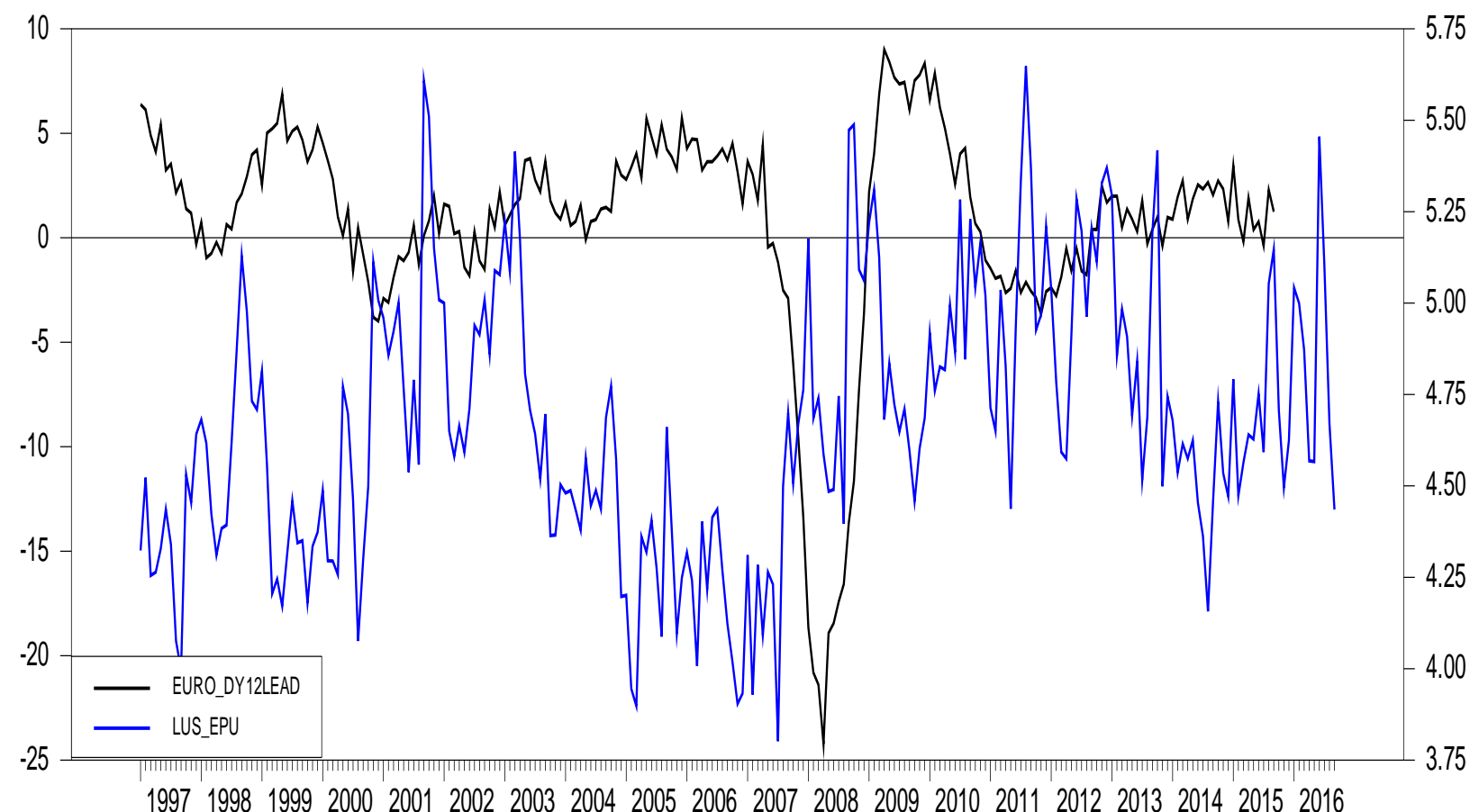

Fig. 3. Future 12-month change in the euro area real economic activity (EURO_DY12LEAD, left scale) and current values of the log of US Economic Policy Uncertainty index (LUS_EPU, right scale).

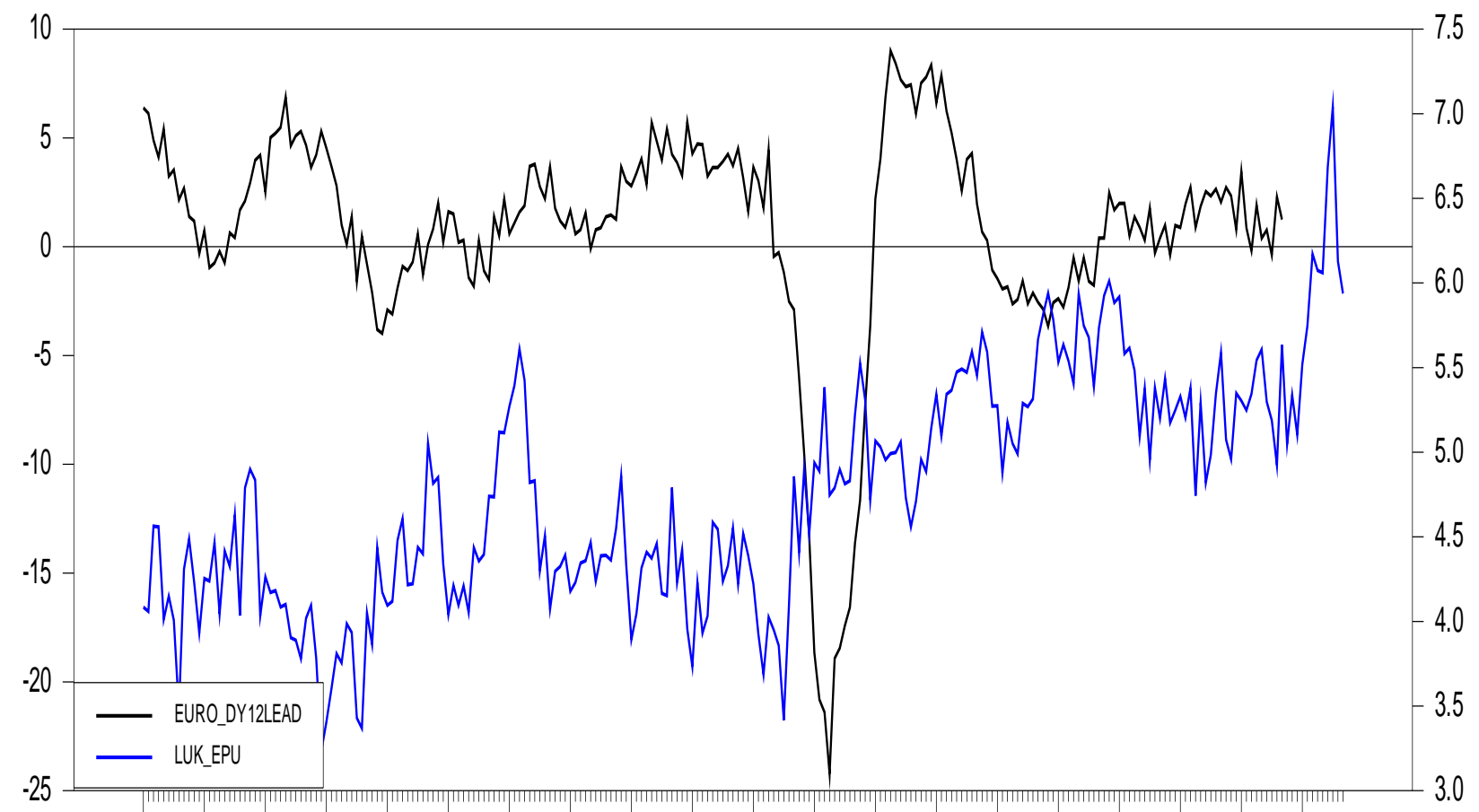

19971998199920002001200220032004200520062007200820092010201120122013201420152016

Fig. 4. Future 12-month change in the euro area real economic activity (EURO_DY12LEAD, left scale) and current values of the log of UK Economic Policy Uncertainty index (LUK_EPU, right scale). 


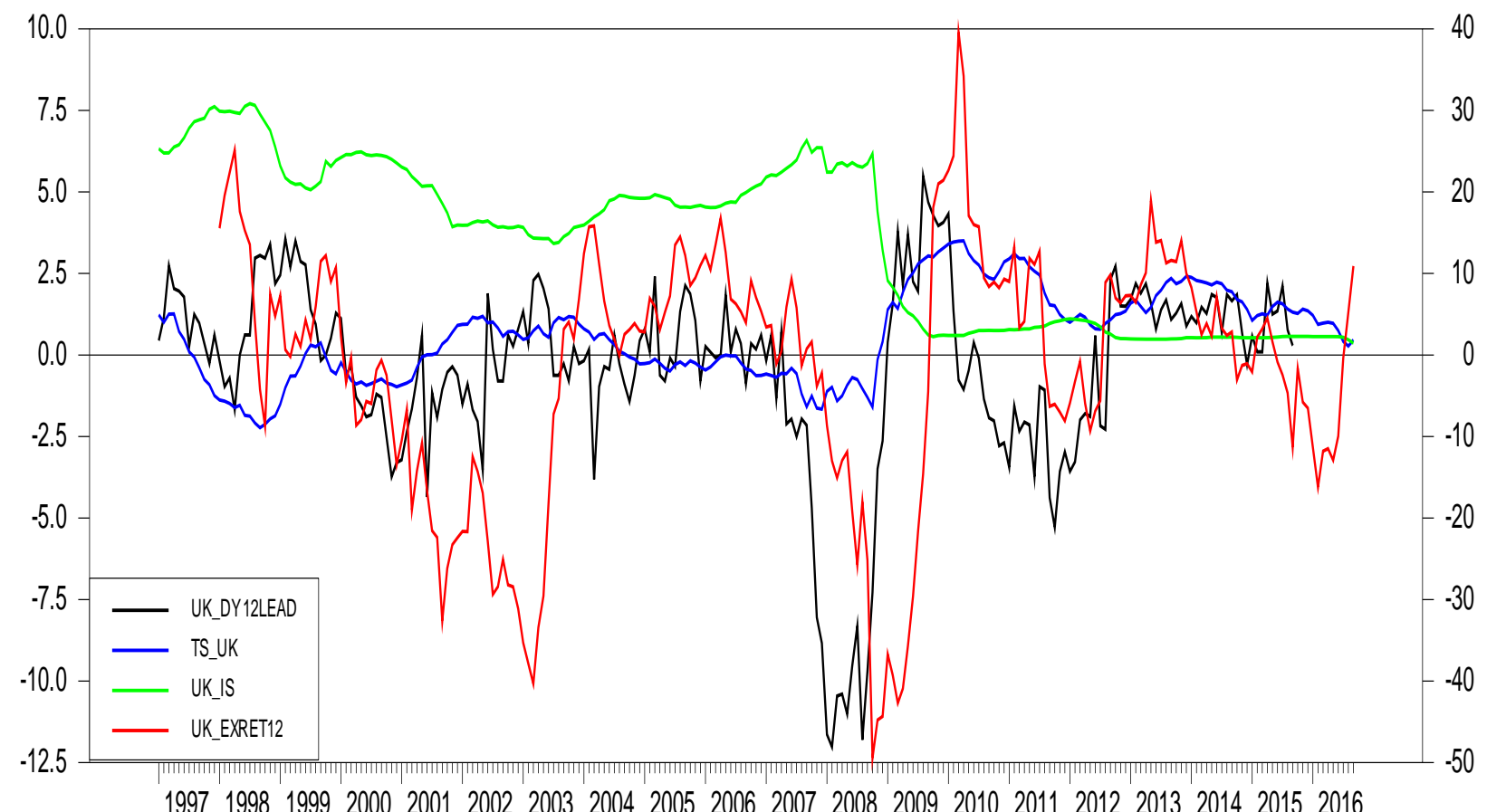

Fig. 5. Future 12-month change in the UK real economic activity (UK_DY12LEAD, left scale), UK short-term (3- month) interest rate (UK_IS, left scale), term spread (TS_UK, left scale), and aggregate excess stock market return in the UK (UK_EXRET12, right scale).

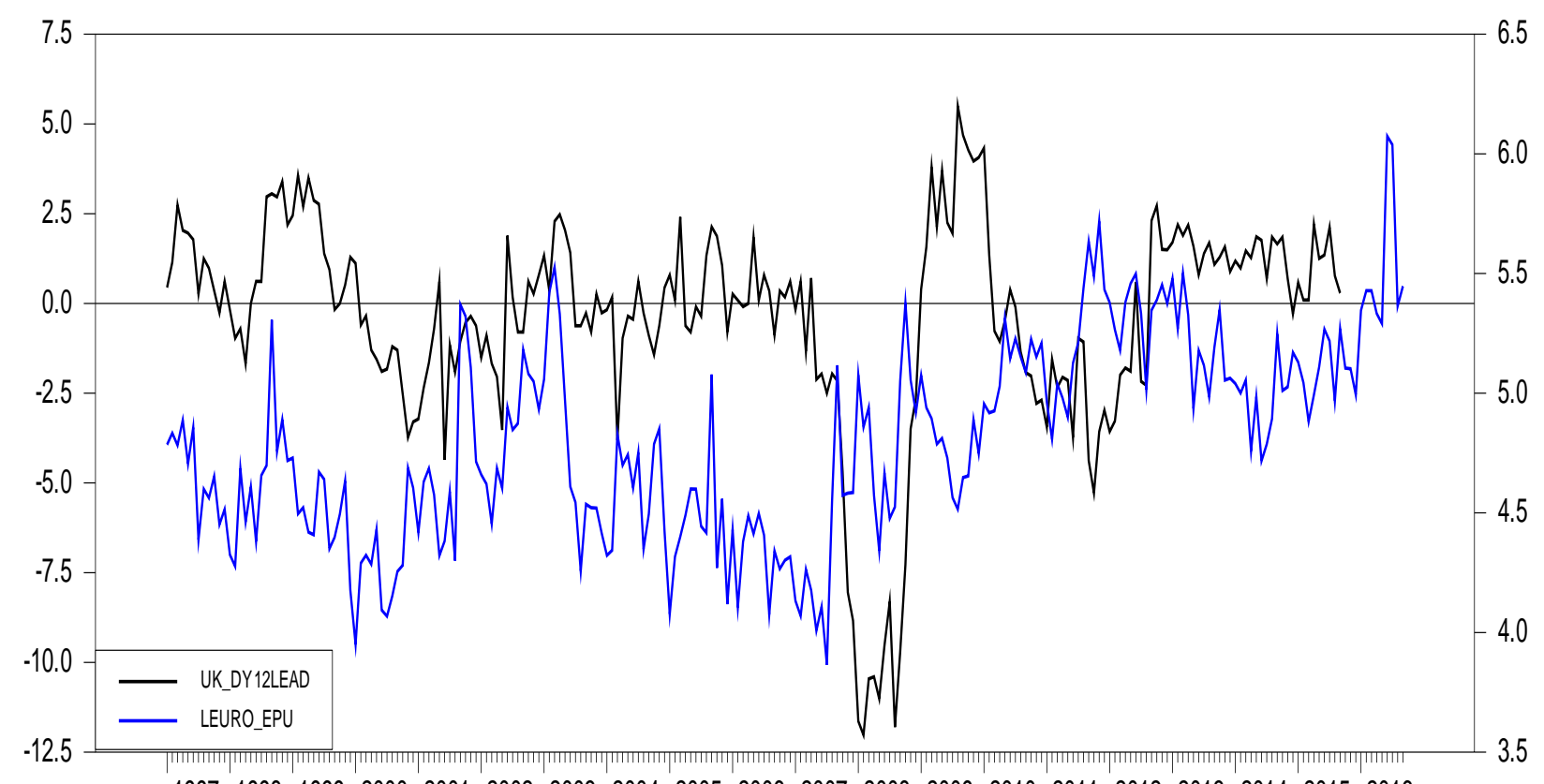

Fig. 6. Future 12-month change in the UK real economic activity (UK_DY12LEAD, left scale) and current values of the log of European Economic Policy Uncertainty index (LEURO_EPU, right scale). 


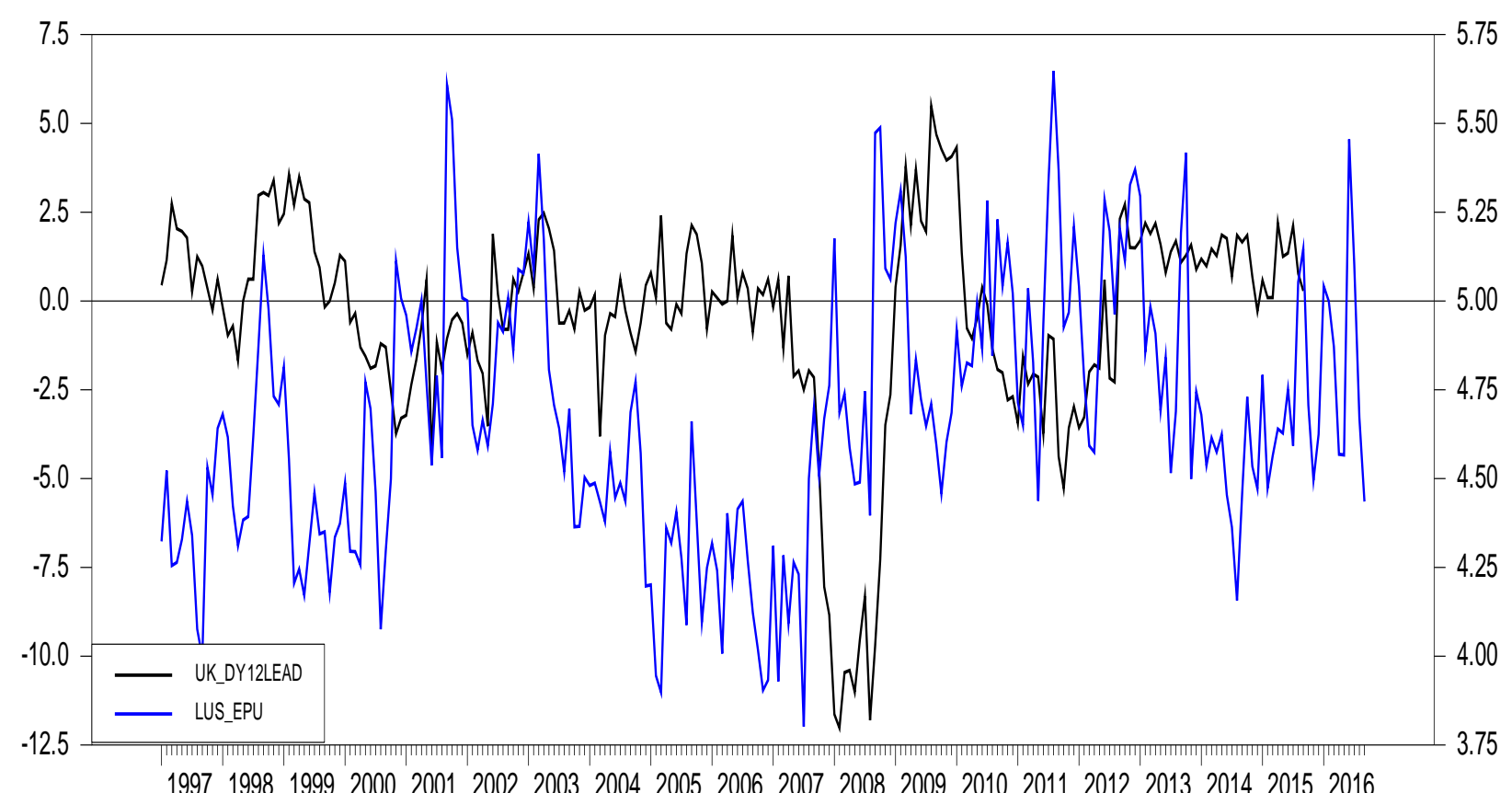

Fig. 7. Future 12-month change in the UK real economic activity (UK_DY12LEAD, left scale) and current values of the log of US Economic Policy Uncertainty index (LUS_EPU, right scale).

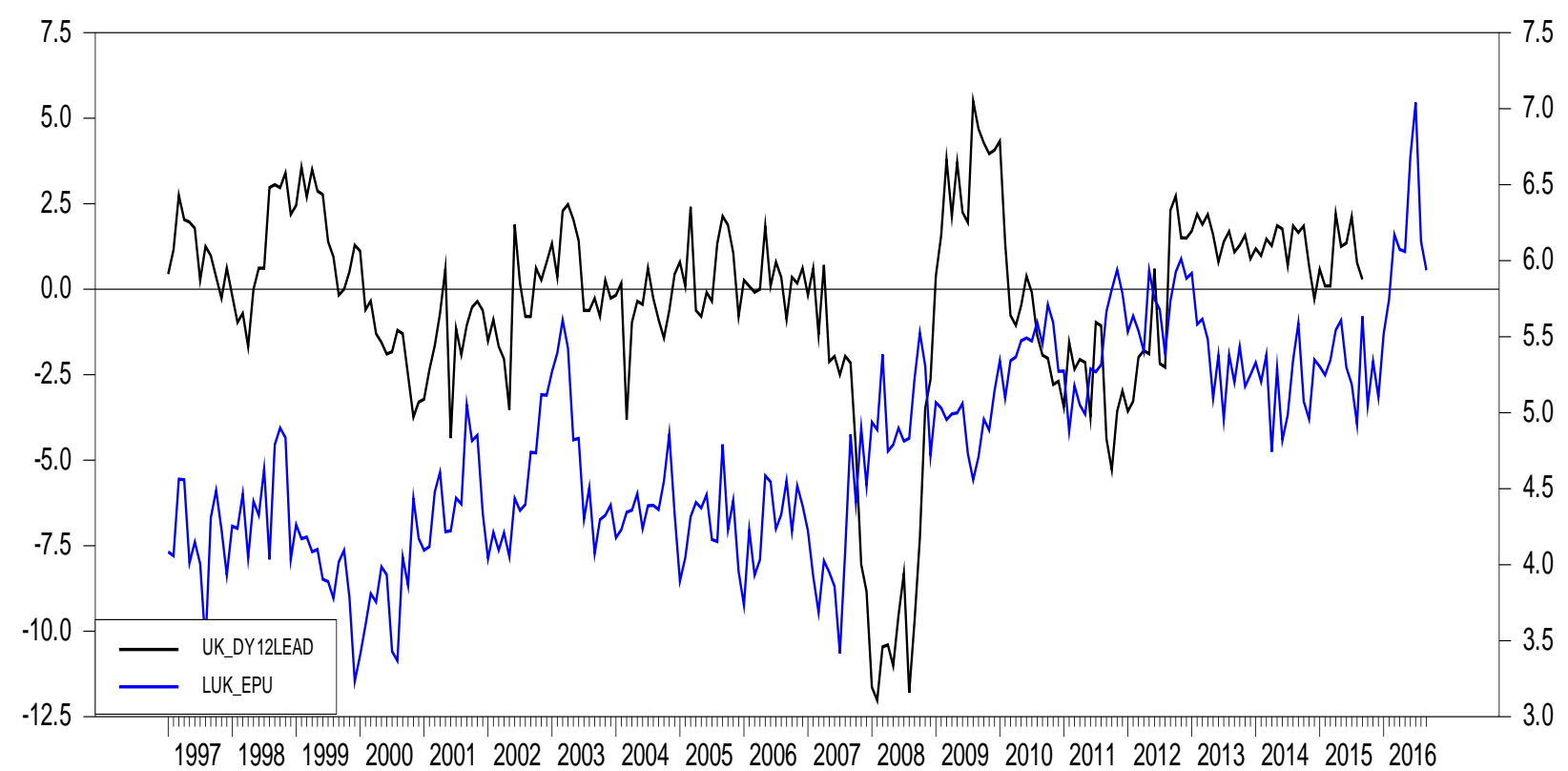

Fig. 8. Future 12-month change in UK real economic activity (UK_DY12LEAD, left scale) and current values of the log of UK Economic Policy Uncertainty index (LUK_EPU, right scale). 